\title{
Evaluation of Ultimate Tensile Strength and Surface Roughness of NiTi and CuNiTi Orthodontic Archwires After Recycling Procedures
}

\author{
Yasmine M. Sayed ${ }^{1}$,Khaled S. Aboulazm ${ }^{2}$, \\ Amal E. Fahmy ${ }^{3}$
}

\section{ABSTRACT:}

Aim: The aim of this study is to evaluate and compare the influence of 2 types of sterilization/disinfection procedures on the tensile strength and surface topography of two orthodontic wires (Nickel-titanium (NiTi), and cupper Nickel-titanium (CuNiTi)). Materials and Methods: Sample comprised of 140 wires $(100$ new $0.017 \times 0.025 "$ Ovoid rectangular, and 40 used $0.017 \times 0.025$ " Ovoid rectangular wires). They were randomly divided into 7 groups according to method and number of sterilization cycles,each group equally divided into 2 subgroups according to wire composition. Surface topography was examined with scanning electron microscope (SEM) and ultimate tensile strength (UTS) was tested using universal testing machine after sterilization and disinfection of the experimental groups. Result: SEM images revealed an increase in surface irregularities in CuNiTi and $\mathcal{N} i T i$ wires after sterilization. UTS of CuNiTi and $\mathcal{N} i T_{i}$ wires after one cycle of autoclave sterilization procedure, or chemical sterilization for one or two cycles were not significantly different when compared with the control group. NiTi and CUNiTi archwires were affected after two cycles of autoclave sterilization. The mean UTS of clinically used and recycled archwires increased significantly when compared with the control group. Used and recycled archwires were affected considerably by autoclave sterilization Conclusion: Autoclave sterilization and chemical sterilization solution can be recommended for sterilization of orthodontic wires for one cycle.

Keywords: Nickel-titanium, cupper $\mathcal{N} i c k e l-$ titanium, sterilization, surface topography, tensile strength

\section{INTRODUCTION}

One of the most important issues currently facing health clinics is the infection control. The health-care providers are striving to achieve, a higher level of protection. Orthodontic wires are frequently packaged in unsterile sealed packs with instructions on the wrapper, generally advising for autoclave sterilization. If sterilization does not alter the properties of wires in an unfavorable direction, there is the possibility for dentists to systematically sterilize wires before placing them in the oral environment. Also reuse of

1- Ass. Lecturer of Orthodontics, Orthodontic Department, Faculty of Dentistry, Pharos University, Alexandria, Egypt*

2- Ass. Professor of Orthodontics, Head of orthodontic department, Faculty of Dentistry, Pharos University, Alexandria, Egypt

3- Professor of dental biomaterials, Dental biomaterials department, Faculty of Dentistry, Pharos University, Alexandria, Egypt

*Corresponding author,Yasmine.mohamed@yahoo.com. 
materials would be of some economic benefit if recycling would not materiallyaffect the properties of the archwires $^{[1]}$. Recycling involves repeated exposure of the wire for several weeks or months to mechanical stresses and elements of the oral environment, as well as sterilization.

Orthodontic wires made from different alloys offer alternative sequences of wire usage during all phases of treatment. Stainless steel (StSt) archwire is one of the most widely used materials in orthodontics. However, nickeltitanium (NiTi) archwire and cupper-nickeltitanium (CuNiTi) are becoming increasingly popular. Stainless steel (SS) archwires remain popular because of their low cost and excellent formability, along with good mechanical properties $^{[2]}$. NiTi wire has super-elastic (SE) and shape memory property ${ }^{[3]}$, and CuNiTi produced gentler forces per unit of deactivation and had substantially more range and higher springback.

Several characteristics of orthodontic wires are considered desirable for optimum performance during treatment. These include a large spring back, low stiffness, high formability, high stored energy, biocompatibility and stability, low surface friction, and the capability to be welded or soldered to auxiliaries. The combined effects of repeated clinical use and sterilization may subject the wire alloy to alteration in its properties ${ }^{[4]}$. The properties of orthodontic wires are commonly determined by means of various laboratory tests. Tension, bending and torsion are uniquely different stress states and place varied demands on wire performance. Graphic description of stress against strain (graph 1) can be used to determine yield strength, modulus of elasticity, stored energy, and spring back when the wire is subjected to tensile loading $^{[5]}$. Tensile properties of a material indicate how it will react to forces applied on it in tension. The surface structure of the orthodontic wire depends on alloy used, complex manufacturing process and the surface finish treatment ${ }^{[6-8]}$. The surface topography of an orthodontic wire is an essential functional property known to influence the mechanical characteristics, esthetic result, corrosion behavior, and biocompatibility of device ${ }^{[2]}$. Surface roughness may modify frictional coefficient and interferes with correct sliding of the bracket along the wire $^{[9,10]}$.

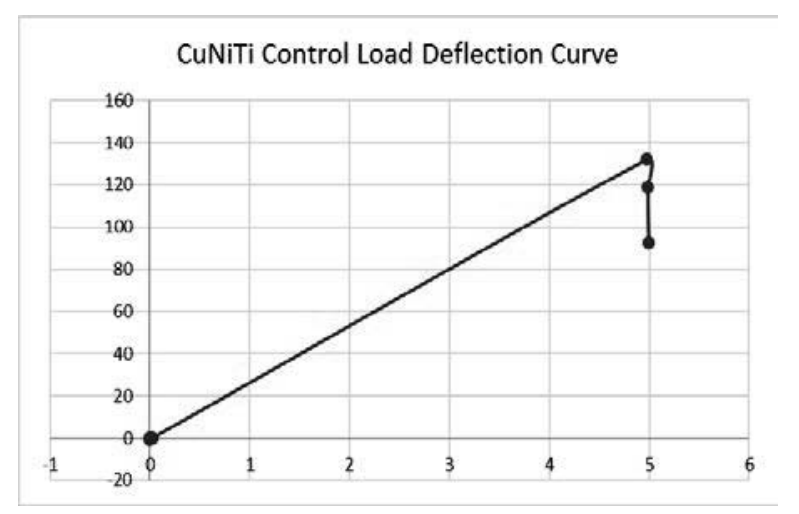

Graph 1: stress-strain curve of CuNiTi wire.

There is considerable debate about whether patients should be treated with recycled and sterilized archwires. The effect of sterilization on tensile properties and surface topography, has not been extensively studied whereas there was no previous studies examined CuNiTi wires. Some previous studies found no alteration in mechanical or physical properties of NiTi wires following dry heat sterilization and autoclave or three cycles of cold sterilization, respectively ${ }^{[11,12]}$. While Kapila et $\mathrm{al}^{[5]}$ reported that dry heat sterilization produced significant changes in the loading and unloading forces associated with NiTi wires. Another study by Smith et $\mathrm{al}^{[1]}$ reported no change in load deflection of NiTi wires after clinical use and sterilization. Staggers and Margeson $^{[13]}$ and Kannan S. ${ }^{[14]}$ observed significant increase in tensile strength of NiTi, when subjected to autoclave and dry heat sterilization. A recent study revealed that 
ultimate tensile strength of clinically retrieved then autoclaved archwires showed significantly lower values when compared with control group and autoclaved as received archwires ${ }^{[15]}$. Pernier et $\mathrm{al}^{[8]}$ observed that sterilization of orthodontic wires did not alter the properties or surface parameters of alloys. While the results of the study by Brindha et al. ${ }^{[16]}$ show that the SEM photographs shows gross increase in pitting roughness of the surface topography after four types of sterilization. Also the SEM images of JojiIsac et al, ${ }^{[17]}$ study revealed an increase in surface irregularities in StSt and NiTi wires after clinical use.

Previous studies have thus given conflicting results especially with NiTi wires and no previous studies on CuNiTi wires, Hence the present study is undertaken to evaluatethe influence of sterilization/disinfection procedures on the tensile strength and surface topography of two orthodontic wires including NiTi, and CuNiTi.

\section{AIM OF THE WORK}

The purpose of this study is to evaluate and compare the effects of sterilization/disinfection on the tensile strength and surface topography of two orthodontic wires ( Nickel-titanium (NiTi), and cupper Nickel-titanium (CuNiTi)) following different number of sterilization cycles of autoclave and $2 \%$ glutaraldehyde solution, to see whether detrimental effects on wire properties are observed by any of these sterilization procedures and to assess whether these sterilization methods are acceptable for orthodontic wires.

\section{MATERIALS AND METHODS}

Sample size and distribution: 70wires of each type: NiTi and CuNiTi (Ormco company) were used: $\left(100\right.$ new $0.017 \times 0.025^{\prime \prime}$ ovoid rectangular, 40 used $0.017 \times 0.025$ " ovoid rectangular wires).Group A comprises 10 wires each of $\mathrm{NiTi}$ (subgroup A1), and CuNiTi (subgroup A2) in their as-received condition from manufacturer to serve as the control group.Group Bincludes 10 wires each of $\mathrm{NiTi}$ (B1), and CuNiTi (B2) which were autoclaved in their asreceived condition from manufacturer 1 cycle.Group $\mathrm{C}$ includes 10 wires each of $\mathrm{NiTi}$ (C1), and CuNiTi (C2) which were autoclaved in their asreceived condition from manufacturer 2 cycles. Group Dincludes 10 wires each of NiTi (D1), and CuNiTi (D2) which were Chemically sterilized in their asreceived condition from manufacturer 1cycle. Group E includes 10 wires each of NiTi (E1), and CuNiTi (E2) which were Chemically sterilized in their asreceived condition from manufacturer 2 cycle. Group Fincludes 10 wires each of NiTi (F1), and CuNiTi (F2) which were used in patient's mouth for 1 month, and then autoclaved 1 cycle.Group G includes 10 wires each of NiTi (G1), and CuNiTi (G2) were used in patient's mouth for 1 month, and then Chemically sterilized.

Exclusion criteria: wires were discarded if bends were placed by clinician or if surface was corroded.

Sterilization methods: Steam Autoclave sterilization protocol of $134{ }^{\circ} \mathrm{C}$ at $2.1 \mathrm{~kg} / \mathrm{cm}$ for 18 minutes (12 minutes sterilization +6 minutes drying period) was performed using an autoclave (millennium B, Faculty of Dentistry, Pharos University in Alexandria). Chemical Sterilization by immersion in biosanitizer (hydrogen peroxide 1\% concentration) for 30 minutes.

\section{Assessment of wires:}

Mechanical properties: A standard tensile test was performed on each of the archwire alloys from all the subgroups (control as well as experimental) using a Universal Testing Machine (Tinius Olsen) at Institute of Graduate Studies and Research, Alexandria University (fig. 1).The ultimate tensile strenth is used to refer to the maximum stress that a material can handle before becoming permanently deformed and fractured. 


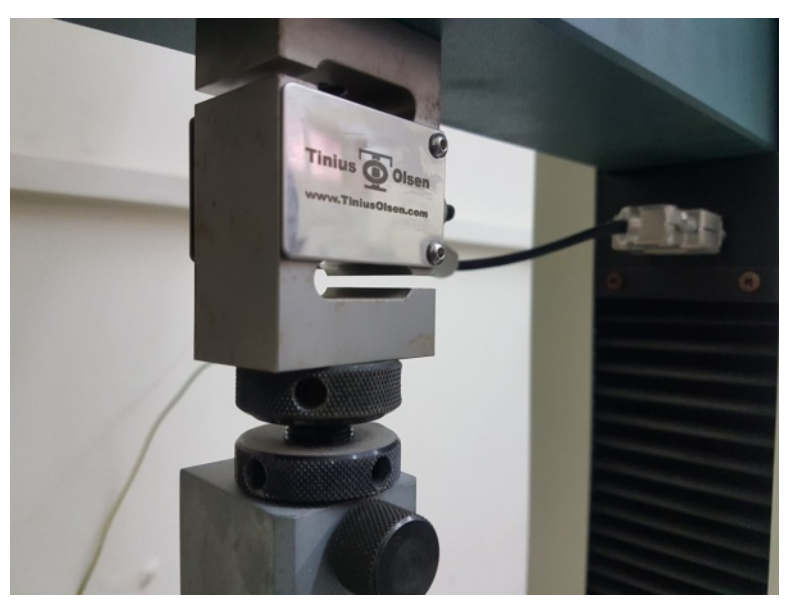

Figure 1: Universal Testing Machine

Surface topography: scanning of specimens from each subgroup was examined using scanning electron microscope (SEM model JSM-530, ×2000 magnifications), at Electron Microscopy Unit, Faculty of Science, Alexandria University.

Methodology: The wires to be autoclaved in Steam Autoclave sterilizer were individually placed into separate storage envelopes (Sterilization flat reel pouch, Libral Traders) with a blue colour indicator which turns brown after sterilization. The autoclave cycle was kept at $134{ }^{\circ} \mathrm{C}$ at $2.1 \mathrm{~kg} / \mathrm{cm}$ for 18 minutes (12 minutes sterilization +6 minutes drying period). At the completion of each cycle, the wires were left to cool at room temperature. This procedure was repeated for all types of wires. Wires for chemical sterilization were placed in biosanitizer (hydrogen peroxide $1 \%$ concentration) for 30 minutes as per manufacturer's recommendations. After sterilization, the wires were rinsed off in running water, laid on absorbent paper, and allowed to air dry. Used wires, after clinical use, were disinfected with an $70 \%$ absolute alcohol (7 parts alcohol and 3 parts distilled water) for 10 minutes, and allowed to air dry before sterilization.
Five inch length $(127 \mathrm{~mm})$ of $0.017 \times 0.025 "$ wires segments were subjected to tension and tested using a Universal Testing Machine. A full scale load of $1000 \mathrm{~N}$ was set in the machine with a crosshead speed of one $\mathrm{mm} /$ minute. The ends of the wire were attached to the fixtures of the universal testing machine out of which one was movable while the other was fixed (fig. 2) The wire was thus stretched until it was fractured at which point the readings were noted. The load taken to break the wire divided by cross-sectional area of the wire will give the value for ultimate tensile strength in Mega Pascal (Mpa). The load deflection data obtained from tensile testing was plotted as stress-strain curves. Same procedure was repeated for each sample.

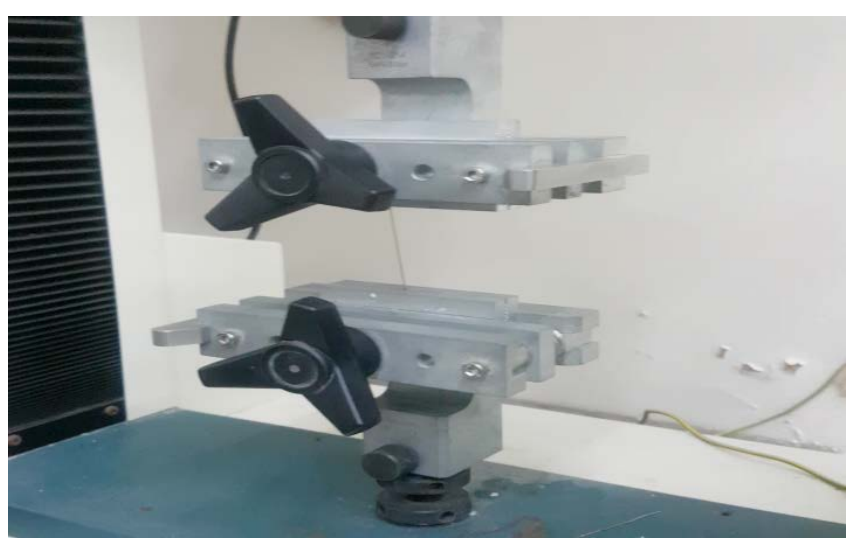

Figure 2: The ends of the wire were attached to the fixtures of the universal testing machine

One $\mathrm{cm}$ long specimen of each alloy wire was placed into the sample holder, sample holder was placed inside specimen chamber of the SEM. Magnification of the sample was then adjusted. The wider surface was scanned and viewed on the monitor (fig. 3). Representative micrographs were obtainedand photographs at $\times 2000$ were recorded to view one representative specimen of anterior segment of archwire from each subgroup to qualitatively characterize the topography of the wire surface. 


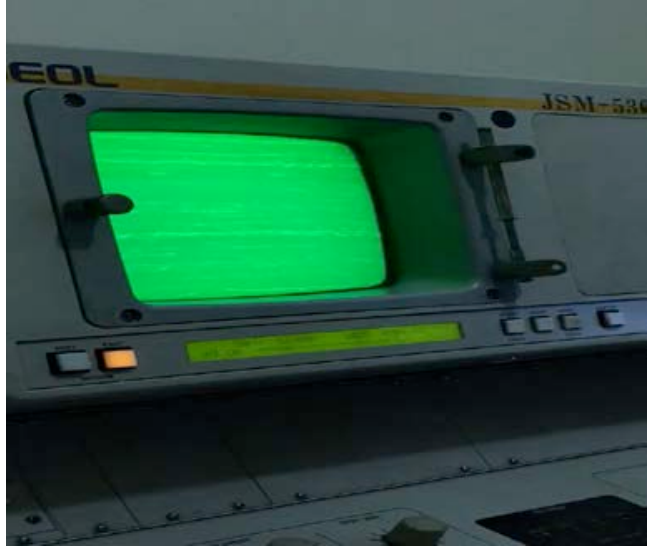

Figure 3: The monitor of the SEM

\section{STATISTICAL ANALYSIS}

SPSS software (IBM) packages version 25 were used for data entry and analysis. Results obtained were analyzed using one-way analysis of variance and Tukey's multiple comparison post-hoc test.

\section{RESULTS}

Surface topography: In the present study,the evaluation of surface topography before and after different methods of sterilization by SEM,as shown in (Fig. 4), suggests the following, Photo micrograph of the SEM images At $\times 2000$ magnification of CuNiTi control group wires showed relatively smooth surface of archwire except for processing marks. Subgroup B2 CuNiTi wires exhibited wider areas of dark spots with localized porosity indicating surface corrosion. There was a wider areas of dark spots randomly located at the archwire surface with increased micro porosity in subgroup C2. While small pits and relatively smooth surface images were showed after chemical sterilization for 1 cycle (subgroup D2). After 2 cycles chemical sterilization (subgroup E2), surface irregularities with larger pits appeared. Photo micrograph of Niti Wire control group demonstrated relatively smooth surface except for processing marks, smooth surface with minor drawing striations after 1 cycle autoclave (subgroup B1), mild surface roughness with small microspores after 2 cycle autoclave (subgroup C1), smooth surface with groove marks due to drawing process of the wire after 1 cycle chemical sterilization (subgroup D1), and Irregularities with groove marks and large pits after 2 cycle chemical sterilization (subgroup E).

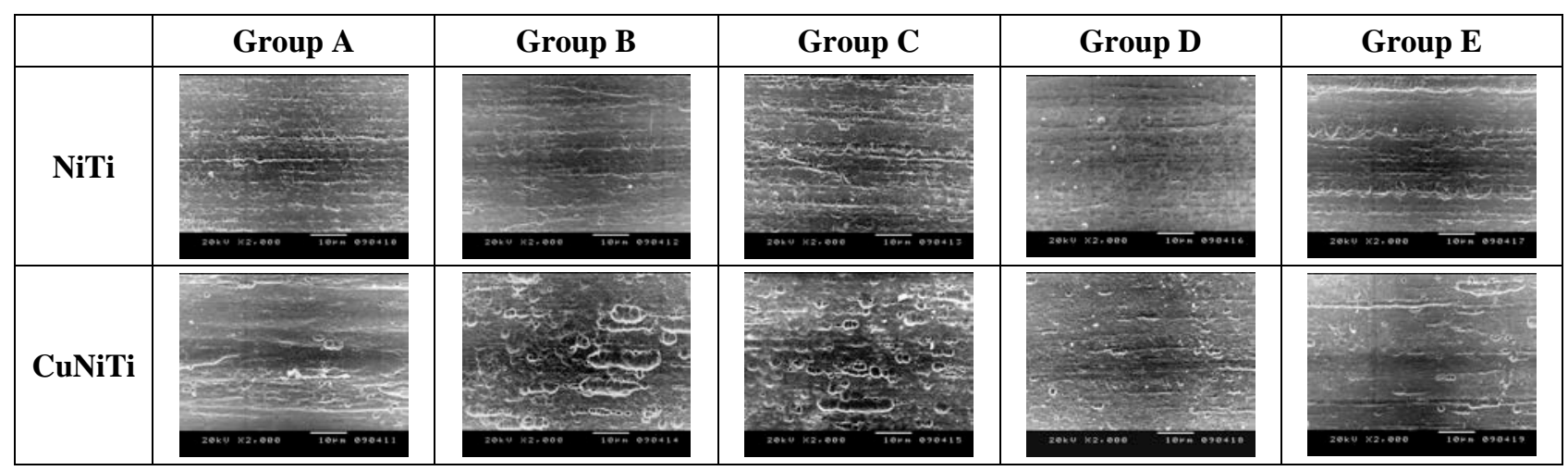

Figure 4: Photo micrograph of the SEM images of NiTi and CuNiTi wires at $\times 2000$ magnification

Ultimate Tensile strength: After measuring the ultimate tensile strength(UTS) in MPaof all the subgroups, the statistical results collected in table 1. According to the new NiTi wires, There was no significant difference between different subgroups after sterilization compared to the control subgroup except subgroup C1 UTS decreased significantly (Fig. 5). Likewise, in comparing CuNiti subgroups, the subgroup which was autoclaved by two cycles recorded a significant decrease in its tensile strength (Fig. 6). While, in accordance to the used NiTi and CuNiTi wires subgroups, there was a significant difference in all subgroups compared to the control subgroup (Fig. 7,8). Recycling wise comparison, by Tukey's multiple comparison post-hoc test is given in table 2 . 
Table 1: Comparison between the ultimate tensile strength of the two studied groups and subgroups in MPa using different sterilization techniques.

\begin{tabular}{|l|l|l|l|l|l|l|}
\hline & $\mathbf{N}$ & Mean & $\begin{array}{c}\text { Std. } \\
\text { Deviation }\end{array}$ & Minimum & Maximum & p-value \\
\hline Control & 10 & 1798.49 & 38.91 & 1726.83 & 1854.30 & \\
Auto1 & 10 & 1770.83 & 38.46 & 1711.88 & 1852.14 & \\
Auto2 & 10 & 1739.60 & 52.47 & 1654.74 & 1832.63 & \\
Chem1 & 10 & 1785.23 & 58.88 & 1695.76 & 1894.13 & \multirow{2}{*}{ (10.000** } \\
Chem2 & 10 & 1777.03 & 40.48 & 1709.83 & 1833.65 & \\
Used Auto & 10 & 1700.50 & 35.31 & 1641.57 & 1747.48 & \\
Used Chem & 10 & 1712.67 & 21.39 & 1676.98 & 1739.32 & \\
Total & 70 & 1754.90 & 53.62 & 1641.57 & 1894.13 & \\
\hline Control & 10 & 1920.29 & 46.06 & 1829.97 & 1973.10 & \\
Auto1 & 10 & 1864.76 & 79.13 & 1719.19 & 2006.34 & \\
Auto2 & 10 & 1776.51 & 64.57 & 1700.39 & 1897.81 & \\
Chem1 & 10 & 1912.09 & 57.33 & 1831.16 & 1974.93 & \\
Chem2 & 10 & 1891.01 & 48.29 & 1832.67 & 1982.33 & $0.000^{* *}$ \\
Used Auto & 10 & 1761.23 & 46.16 & 1700.21 & 1857.82 & \\
Used Chem & 10 & 1794.78 & 59.83 & 1714.01 & 1902.40 & \\
Total & 70 & 1845.81 & 83.75 & 1700.21 & 2006.34 & \\
\hline
\end{tabular}

* Significant at p-value $<0.05$. ** Highly Significant at p-value $<0.001$.

Table 2: Tukey's multiple comparison post-hoc test between different subgroups.

\begin{tabular}{|l|c|c|c|c|c|c|}
\hline NiTi & A1 & B1 & C1 & D1 & E1 & F1 \\
\hline B1 & 0.767 & & & & & \\
\hline C1 & $0.042^{*}$ & 0.652 & & & & \\
\hline D1 & 0.992 & 0.988 & 0.212 & & & \\
\hline E1 & 0.915 & 0.999 & 0.440 & 0.999 & & \\
\hline F1 & $0.000^{* *}$ & $0.008^{*}$ & 0.386 & $0.001^{* *}$ & $0.003^{*}$ & \\
\hline G1 & $0.001^{* *}$ & $0.047^{*}$ & 0.788 & 0.005 & $0.019^{*}$ & 0.995 \\
\hline CuNiTi & $\mathrm{A} 1$ & $\mathrm{~B} 1$ & $\mathrm{C} 1$ & $\mathrm{D} 1$ & $\mathrm{E} 1$ & $\mathrm{~F} 1$ \\
\hline B1 & 0.351 & & & & & \\
\hline C1 & $0.000^{* *}$ & $0.020^{*}$ & & & & \\
\hline D1 & 0.999 & 0.545 & $0.000^{* *}$ & & & \\
\hline E1 & 0.919 & 0.951 & $0.001^{* *}$ & 0.983 & & \\
\hline F1 & $0.000^{* *}$ & $0.003^{*}$ & 0.997 & $0.000^{* *}$ & $0.000^{* *}$ & \\
\hline G1 & $0.000^{* *}$ & 0.121 & 0.992 & $0.001^{* *}$ & $0.008^{*}$ & 0.856 \\
\hline
\end{tabular}

\footnotetext{
* Significant at p-value $<0.05$. ** Highly Significant at p-value $<0.001$.
} 


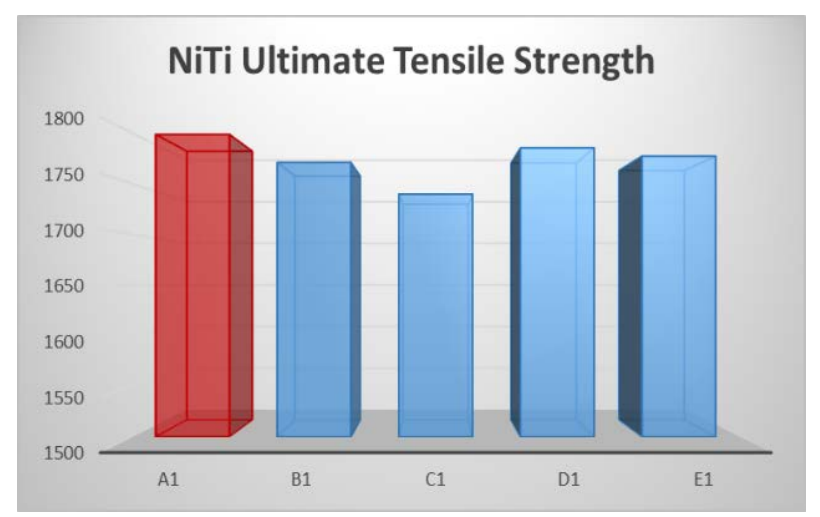

Figure 5: Comparison between the ultimate tensile strength of new NiTiarchwirestudied subgroups in $\mathrm{MPa}$ using different sterilization techniques.

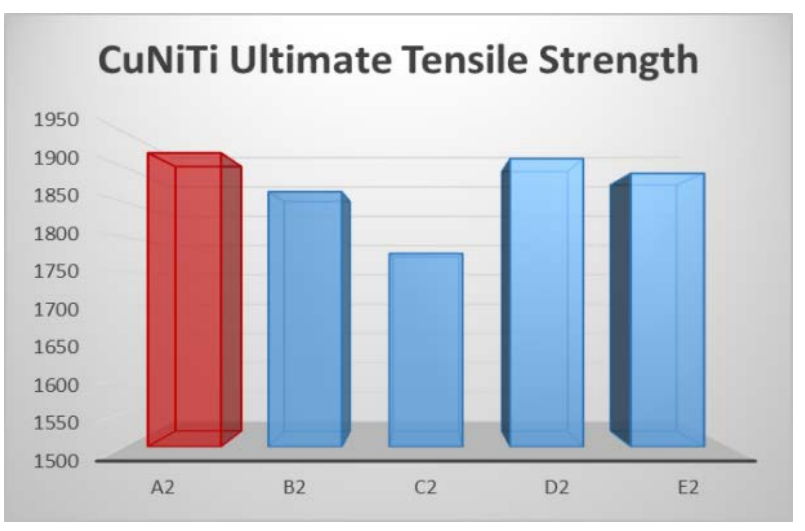

Figure 6: Comparison between the ultimate tensile strength of new CuNiTiarchwirestudied subgroups in MPa using different sterilization techniques.

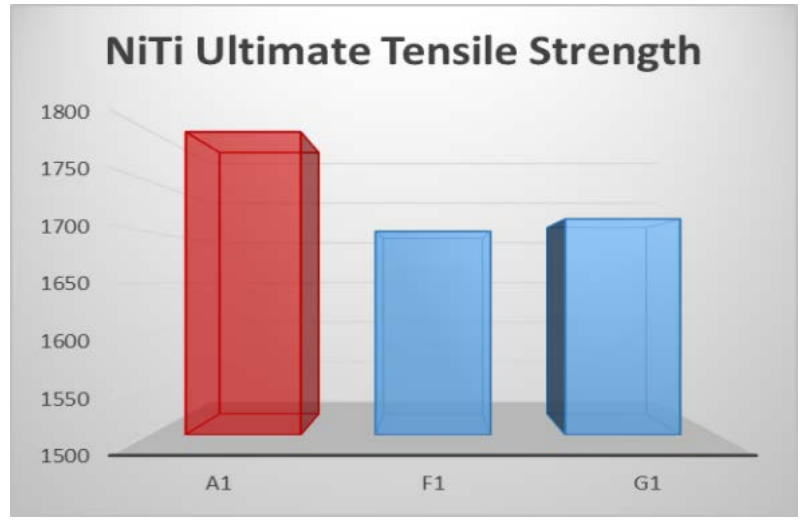

Figure 7: Comparison between the ultimate tensile strength of used NiTi archwire studied subgroups and control subgroup in MPa using different sterilization techniques.

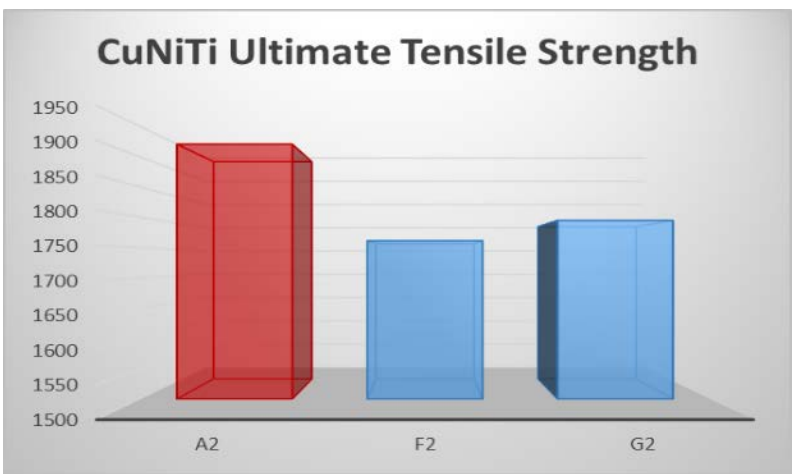

Figure 8: Comparison between the ultimate tensile strength of used CuNiTi archwire studied subgroups and control subgroup in $\mathrm{MPa}$ using different sterilization techniques.

Table 3: Comparison between the ultimate tensile strength of the two studied groups and subgroups in MPa using different sterilization techniques.

\begin{tabular}{|c|c|c|c|c|c|}
\hline & & $\mathbf{N}$ & Mean & SD & p-value \\
\hline \multirow{2}{*}{ A } & NITi & 10 & 1798.49 & 38.91 & \multirow{2}{*}{$0.000 * *$} \\
\hline & CuNiTi & 10 & 1920.29 & 46.06 & \\
\hline \multirow{2}{*}{ B } & NITi & 10 & 1770.83 & 38.46 & \multirow{2}{*}{$0.003^{*}$} \\
\hline & CuNiTi & 10 & 1864.76 & 79.13 & \\
\hline \multirow{2}{*}{ C } & NITi & 10 & 1739.60 & 52.47 & \multirow{2}{*}{0.178} \\
\hline & CuNiTi & 10 & 1776.51 & 64.57 & \\
\hline \multirow{2}{*}{ D } & NITi & 10 & 1785.23 & 58.88 & \multirow{2}{*}{$0.000 * *$} \\
\hline & CuNiTi & 10 & 1912.09 & 57.33 & \\
\hline \multirow{2}{*}{$\mathbf{E}$} & NITi & 10 & 1777.03 & 40.48 & \multirow{2}{*}{$0.000 * *$} \\
\hline & CuNiTi & 10 & 1891.01 & 48.29 & \\
\hline \multirow{2}{*}{$\mathbf{F}$} & NITi & 10 & 1700.50 & 35.31 & \multirow{2}{*}{$0.004 *$} \\
\hline & CuNiTi & 10 & 1761.23 & 46.16 & \\
\hline \multirow{2}{*}{ G } & NITi & 10 & 1712.67 & 21.39 & \multirow{2}{*}{$0.001^{* *}$} \\
\hline & CuNiTi & 10 & 1794.78 & 59.83 & \\
\hline
\end{tabular}

* Significant at p-value $<0.05 . \quad * *$ Highly Significant at p-value $<0.001$. 
Group-wise comparison, irrespective of sterilization, is given in table 3 . The UTS $\mathrm{s}$ hows a significant increase in the CuNiTi control subgroup compared to the NiTi control subgroup (graph 2), also there was a highly significant difference between the two subgroups which were used and subjected to the autoclave by one cycles (Fig. 9).

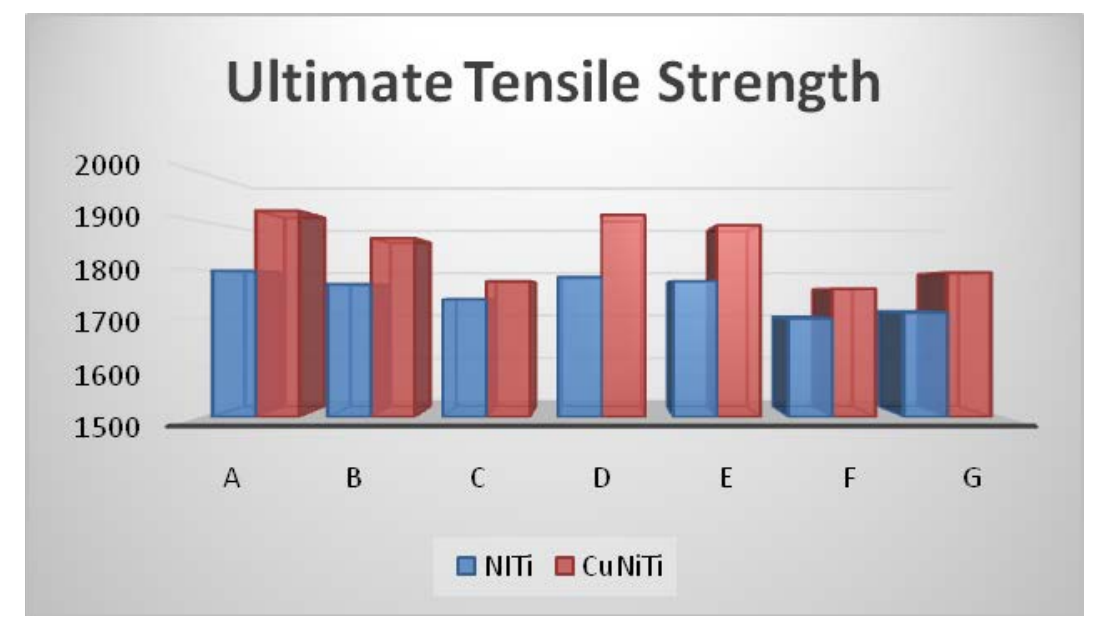

Figure 9: Comparison between the ultimate tensile strength of the two studied groups and subgroups in MPa using different sterilization techniques.

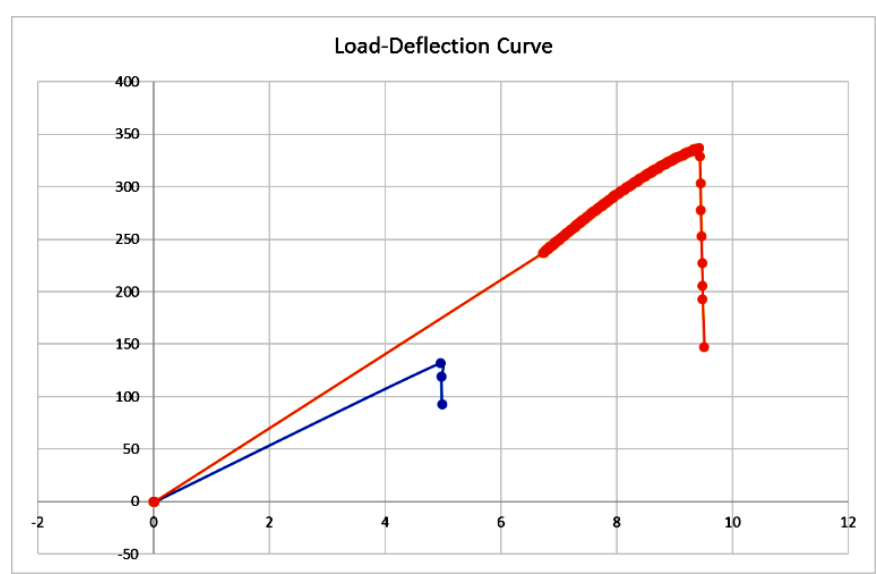

Graph 2: Comparison between UTS of the control NiTi (blue) and CuNiTi(orange) subgroups.

\section{DISCUSSION}

Surface topography: The surface structure of an orthodontic archwire is an essential functional property known to influence the esthetic result, the corrosion behavior and the biocompatibility of devices ${ }^{[4]}$. Furthermore, plaque accumulation is also affected by surface roughness variation and this in turn has a key role in corrosion behavior and esthetics. The surface properties such as roughness, hardness, and topography of orthodontic archwires may affect the sliding mechanics by influencing the coefficient of friction between the archwire and bracket. However, the relationship comprising roughness and frictional forces existing between wire and brackets is more complex and not yettotally clear.In the present study, surface topography of archwires was evaluated by SEM at $\times 2000$ magnifications. Each archwire specimen appeared to have its characteristic surface structure. Control wires showed relatively smooth surface with striations 
parallel to long axis. These may be related to mechanical impact during manufacturing ${ }^{[18]}$. Pitting pattern was also noticed, which may be resulted from chemical interactions during manufacturing. Scratches not parallel to long axis were observed on some samples. NiTi wires showed more indentations and pitting corrosion after recycling. Surface irregularities observed in NiTi archwires are sites susceptible to the selective dissolution of $\mathrm{Ni}$, may arise from manufacturing process and the patterns differs with various manufacturers ${ }^{[19]}$. There was wider areas of dark spots randomly located at the archwire surface with increased micro porosity due to loss of $\mathrm{NiTi}$ particles in subgroup C2.

The results of the SEM evaluation of the wires in the present study is contrary to observations of Grosgogeat et al. ${ }^{[20]}$ who conducted a study to determine the influence of sterilization and surface treatment on the orthodontic archwire friction coefficient. The sterilization process and surface treatment induced no significant modification of the tribiological properties of SS and TMA wires.The increased roughness is due to sterilization, which removes debris or traces of grease which might have remained on the wires after their production, which would have made the real surface roughness to the control wires more difficult to observe.

However, the increase in surface roughness was less to cause any clinical effect. The differences are only perceptible when an extremely precise measurement tool is used.

Ultimate Tensile strength: After measuring the ultimate tensile strength (UTS) of new NiTi wires in $\mathrm{MPa}$, There was no significant difference between different subgroups after sterilization compared to the control subgroup except subgroup C1 UTS decreased significantly (Fig. 5). Likewise, in comparing CuNiti subgroups, the subgroup which was autoclaved by two cycles recorded a significant decrease in its tensile strength (Fig. 6). While, in accordance to the used NiTi and CuNiTi wires subgroups, there was a significantdifference in all subgroups compared to the control subgroup (Fig. 7,8). Recycling wise comparison, by Tukey's multiple comparison post-hoc test is given in table 1.

Mechanical properties are expressed most often in units of stress or strain. Stress is force per unit area within a structure subjected to an elastic force or pressure where as a strain is change in length per unit length and is the relative deformation of an object subjected to a stress ${ }^{[21]}$. The elastic behaviour of any material is defined in terms of stress-strain response to an external load, both of which correspond to the internal state of the material being studied. A tensile test is recommended for evaluation of stress-strain behaviour, where an entire piece of alloy archwire reaches the elastic limit at the same time ${ }^{[22]}$.

In the present study we evaluated UTS in $\mathrm{MPa}$. Changes in the tensile strength will have a direct impact on the clinical use of wire. If a wire's ultimate tensile strength is decreased, it is more prone to breakage which presents a problem for patient and the orthodontist alike ${ }^{[13]}$. Wentz concluded that the impacts of sterilization on wires are related to wire type and sterilization method ${ }^{[23]}$.Upon tensile evaluation ofnewwires after 2 cycles autoclave sterilization, ultimate tensile strength was found significantly reduced which is in accordance with JojiIsac et al. ${ }^{[15]}$. It is possible that high temperatures from autoclave sterilization has an effect on NiTi and CuNiTi archwires $^{[1]}$. Autoclave also significantly increased the tensile strength of NiTi wire.

When UTS of clinically used wires were compared with control wires, a significant reduction in ultimate tensile strength was found, these findings are supported by JojiIsac et al. ${ }^{[15]}$ and Kapila et al. who reported considerable 
impairment of mechanical properties of NiTi wires when a combination of sterilization and clinical reapplication was studied. The increase in stiffness of NiTi wires after clinical recycling may have resulted because of work hardening as a consequence of repetitive intraoral mechanical stresses to which wires were exposed during clinical use ${ }^{[4]}$.The present study evaluated only UTS properties and were performed using a standard tensile test and the values may differ from other studies performed using a three point bending test.

\section{CONCLUSION}

On the basis of the results obtained after SEM and UTS evaluation, the conclusion of the current study can be summarized as follows:

- There was a significant increase in surface roughness of archwires after sterilization,

- The control CuNiTi arch wires presented more strength in tension than the NiTi,

- One cyclesterilization by using Autoclave and chemical sterilization did not affect considerably on mechanical properties of archwires, while NiTi and CuNiTi archwires were affected after two cycles of autoclave sterilization,

- Used and recycled arch wires were affected considerably by autoclave sterilization,

- Autoclave sterilization, and biosanitizer chemical sterilization solution can be safely recommended for sterilization of orthodontic wires for one cycle.

\section{REFERANCES}

1. Smith, G. A., Von Fraunhofer, J. A., \& Casey, G. R. The effect of clinical use and sterilization on selected orthodontic archwires. American Journal of Orthodontics and Dentofacial Orthopedics,1992;102; 153-159.
2. Daems, J., Celis, J. P., \& Willems, G. Morphological characterization of as-received and in vivo orthodontic stainless steel archwires. The European Journal of Orthodontics. 2009;31; 260-265.

3. Eliades $\mathrm{T}$, Eliades $\mathrm{G}$, Athanasiou AE, Bradley TG. Surface characterization of retrieved NiTi orthodontic archwires. Eur J Orthod.; 2000;22; 317-326.

4. Kapila S, Haugen JW, Watanabe LG. Load-deflection characteristics of nickel-titanium alloy wires after clinical recycling and dry heat sterilization. Am J OrthodDentofacialOrthop 1992;102;120-126.

5. Kapila, S., \&Sachdeva, R. Mechanical properties and clinical applications of orthodontic wires. American Journal of Orthodontics and Dentofacial Orthopedics,1989;96; 100-109.

6. Bourauel C, Fries T, Drescher D, Plietsch R. Surface roughness of orthodontic wires via atomic force microscopy, laser specular reflectance, and profilometry. Eur J Orthod 1998;20; 79-92.

7. Neumann P, Bourauel C, Jäger A. Corrosion and permanent fracture resistance of coated and conventional orthodontic wires. J Mater Sci Mater Med 2002;13:141-147.

8. Pernier C, Grosgogeat B, Ponsonnet L, Benay G, Lissac M. Influence of autoclave sterilization on the surface parameters and mechanical properties of six orthodontic wires. Eur J Orthod 2005;27; 72-81.

9. Tselepis M, Brockhurst P, West VC. The dynamic frictional resistance between orthodontic brackets and archwires. Am J OrthodDentofacialOrthop 1994;106; 131-138.

10. Downing A, McCabe J, Gordon P. A study of frictional forces between orthodontic brackets andarchwires. Br J Orthod 1994;21; 349-357.

11. Mayhew MJ, Kusy R. Effects of sterilization on the mechanicalproperties and surface topography of nickel-titanium archwires.Am J Orthod and DentofacOrthop 1988;93; 232-236. 
12. Buckthal JE, Kusy RP. Effects of cold disinfectants on the mechanical properties and surface topography of nickeltitanium archwires. Am J OrthodDentofacOrthop1988;94:117-122.

13. Staggers JA, Margeson D. Effects of sterilization on the tensile strength of orthodontic wires. The Angle Orthodontist1993;63; 141-144.

14. Kannan S, Kapoor DN, Tandon P, Gupta A. Evaluation of Effects of Sterilization on Mechanical Properties of OrthodonticWires. J IndOrthodSoc 2012;46; 126-131.

15. Jojilsac, Mahendra. S, B.S Chandrashekar, Vinay P. Reddy, Ramesh Kumar P. C, Bala Mohan Shetty. Effects of clinical recycling on mechanical properties of three commonly usedtypes of orthodontic archwires, Saudi J. Oral. Dent. Res.; 2016;1; 124-136.

16. Brindha M., Kurunji N.K., Rajasigamani K. Evaluation of tensile strength and surface topography of orthodontic wires after infection control procedures: An in vitro study,Ntal Science, 2014; 6;44-48.

17. Jojilsac, BS Chandrashekar, $\mathrm{S}$ Mahendra, CM Mahesh, Bala Mohan Shetty, AV Arun, Effects of clinical use and sterilization on surface topography and surface roughness of three commonly used types of orthodontic archwires, Original Research, 2015; 26; 378-383.
18. Crotty OP, Davies EH, Jones SP. The effects of cross-infection control procedures on the tensile and flexural properties of superelastic nickel-titanium wires. Br. J.Orthod 1996; 23; 37-41.

19. Buckthal JE, Mayhew MJ, Kusy RP, Crawford JJ. Survey of sterilization and disinfection procedures. J ClinOrthod 1986;20; 759-765.

20. Grosgogeat B, Jablonska E, Vernet JM, Jaffrezic N, Lissac M, Ponsonnet L. Tribological response of sterilized and un-sterilized orthodontic wires. Mater Sci. Eng. C. Mater Biol. Appl. 2006; 26; 267-272.

21. Anusavice, K. J., Shen, C., \& Rawls, H. R. Phillips' science of dental materials. Elsevier Health Sciences, 2013.

22. Oltjen, J. M., Duncanson Jr, M. G., Ghosh, J., Nanda, R. S., \&Frans Currier, G. Stiffness-deflection behavior of selected orthodontic wires. The Angle Orthodontist, 1997; 67, 209-218.

23. Meling, T. R., \&Ødegaard, J. Short-term temperature changes influence the force exerted by superelastic nickel-titanium archwires activated in orthodontic bending. American journal of orthodontics and dentofacial orthopedics,1998; 114; 503-509. 